\title{
Las maternidades contemporáneas en dos obras de ficción
}

\section{Contemporary maternities in two works of fiction}

\author{
Cristina Palomar Verea* \\ Karla Alejandra Contreras Tinoco**
}

\section{Resumen}

Las obras de ficción reproducen estereotipos, deseos y roles de los sujetos sociales, a la vez que construyen referentes, modelos y estilos de vida ideales. En este trabajo analizamos lo significados relacionados con la maternidad contemporánea en dos piezas de ficción. Las obras analizadas son la serie televisiva "Pequeña Victoria" y la obra literaria "Feliz Final". En los resultados se destaca un modelo de maternidad intensiva, el ideal de una maternidad colectiva entre mujeres y sin hombres, y tensiones generacionales entre mujeres relacionadas con la crianza y el cuidado de los infantes.

Palabras Clave: maternidad, consumo cultural, identidades, feminismo, amor maternal

\begin{abstract}
The works of fiction reproduce stereotypes, desires and roles of the social subjects, at the same time that they construct referents, models and ideal lifestyles. In this work we analyze the meanings related to contemporary motherhood in two fictional pieces. The works analyzed are the television series "Little Victory" and the literary work "Happy Ending". The results highlight an intensive motherhood model, the ideal of a collective motherhood between women and without men, and generational tensions between women related to the upbringing and care of infants.

\footnotetext{
* Doctora en Ciencias Sociales con especialidad en Antropología Social por el Centro de Investigación y Estudios Superiores en Antropología Social-Occidente y la Universidad de Guadalajara. Formación en Psicoanálisis Individual, en el Círculo Psicoanalítico Mexicano, A.C. Licenciatura en Psicología en el Instituto Tecnológico y de Estudios Superiores de Occidente, en Guadalajara, México. Profesora e Investigadora en el Centro Universitario de Ciencias Sociales y Humanidades, Universidad de Guadalajara, México. crispalvertina@hotmail.com ORCID: https://orcid.org/0000-0001-7075-3460

** Doctora en Ciencias Sociales con especialidad en Antropología Social por el Centro de Invesitgación y Estudios Superiores en Antropología Social- Occidente. Maestra en Psicología Social por la Universidad Católica del Norte, Chile. Licenciada en Psicología por la Universidad de Guadalajara. Profesora en el Centro Universitario de la Ciénega, Universidad de Guadalajara. ctka28@hotmail.com ORCID: https://orcid.org/0000-0001-6061-4600
} 
Revista Punto Género N.ㅇ 15 Junio de 2021

ISSN 0719-0417 / 181-200

Keywords: motherhood, cultural consumption, identities, feminism, maternal love

Fecha de recepción: Octubre 2020

Fecha de aprobación: Junio 2021

\section{Introducción}

Los nuevos significados que la maternidad parece tener actualmente y las nuevas maneras de vivir esta experiencia por parte de las mujeres en edad reproductiva hablan de la aparición de formas inéditas de entender los vínculos sociales, las identidades y el género. A partir de esta afirmación, nos preguntamos, ¿qué significa la maternidad en la segunda década del siglo XXI? ¿Qué supuestos entrañan las nuevas formas de maternidad en relación con los vínculos sociales? ¿Cómo se conecta este significado con las expresiones feministas contemporáneas? ¿Cómo se refleja todo esto en la cultura de ficción?

En un intento por obtener pistas para responder las preguntas planteadas, nos proponemos analizar dos piezas de ficción, una televisiva y otra literaria. Estas obras presentan justamente el tema de las nuevas formas de vivir y entender la experiencia de la maternidad. Hemos elegido una serie de televisión que diversos autores (Erbiti, 2019; Freijo, 2019) han propuesto como rupturista y feminista, para analizar las continuidades y las transformaciones en las formas actuales de vivir la maternidad, y una novela reciente que explora las maneras de vivir los afectos en nuestros días, incluyendo los relacionados con la pareja y los hijos.

Consideramos que las obras de ficción seleccionadas reflejan los componentes y características que distinguen a las maternidades contemporáneas. Algunos investigadores (Bueno; 2006; Galán, 2006; Pacheco, 2009 citado en Hidalgo-Mari, 2017) han destacado que en las prácticas expresivas (televisión, streaming, narrativa) se reflejan y presentan radiografías de las discusiones y condiciones que caracterizan a las sociedades de una determinada época y contexto. De Lauretis (1992) señaló que las prácticas expresivas como el cine implican la producción de signos que captan y presentan el mundo "natural" de una determinada ideología, por ejemplo, de la ideología dominante.

Sostenemos que las obras de ficción participan en la producción del género y de los ideales relacionados con la maternidad, en tanto fenómeno de género. Diversos autores (Bueno, 2006; Galán, 2006; Guarinos, Gordillo, Ramírez-Alvarado, Jiménez \& Hermida, 2019, 2019; Menéndez \& Zurian, 2014; Sarlo, 1997 citado en Bueno, 2006; Simelio, 2010) han señalado que los medios de comunicación como la televisión producen nuevos modelos de existencia y generan deseos, aspiraciones, gustos y estilos de vida, así como transmiten roles, estereotipos o normativas que orientan la construcción de la identidad y que tienen impacto en la cotidianidad de las personas.

Para De Lauretis (1992), en medios como el cine se crean y recrean las identidades y las subjetividades a través de las representaciones que construyen y muestran. Particularmente, la autora dice: 
Podemos, entonces, entender la representación cinematográfica más específicamente como un tipo de proyección de la visión social sobre la subjetividad. En otras palabras, el hecho de que el cine asocie la fantasía a imágenes significantes afecta al espectador como una producción subjetiva, y, por ello, el desarrollo de la película inscribe y orienta, de hecho, el deseo. De esta forma, el cine participa poderosamente en la producción de formas de subjetividad que están modeladas individualmente, pero son inequívocamente sociales (De Lauretis, 1992, p. 19).

El procedimiento seguido para este trabajo fue que dos investigadoras independientes observamos por separado cada una de las obras de ficción para luego hacer una síntesis de ambos recursos, así como una transcripción de las escenas, episodios o fragmentos relacionados con el tema de la maternidad que aparecen en dichas obras.

Posteriormente, hicimos un análisis semiótico global de la serie y de los fragmentos seleccionados. Para ello, asumimos el principio de que el significado se construye y es producto de códigos culturales compartidos, tal como lo señala De Lauretis (1992). Esta autora afirma que la teoría postestructuralista de la semiosis tiene dos corrientes: una, centrada en los aspectos subjetivos de la significación, y la otra, que acentúa el aspecto social del significado, es decir, su uso práctico, estético o ideológico en la comunicación. En esta segunda corriente es en la que este trabajo se inscribe. El foco de nuestro interés está en estudiar y comprender las formas y características de la maternidad que se presenta en las dos obras, así como en analizar el sentido de las prácticas maternales mostradas en estas. El análisis inició en noviembre de 2019 y concluyó en junio de 2020.

Las dos obras de ficción analizadas son la serie argentina titulada Pequeña Victoria y la novela titulada Feliz Final, del español Isaac Rosa (Seix Barral, Barcelona, 2018). A continuación, se presenta una breve síntesis de la serie "Pequeña Victoria" para después presentar una síntesis de "Feliz Final". Luego se analizan las diferencias y similitudes en cuanto a significados, características y experiencias de maternidad que se representan en las dos obras. Finalmente, se hacen algunas reflexiones críticas.

\section{Presentación general de "Pequeña Victoria" y "Feliz final"}

\section{La serie "Pequeña Victoria": una aproximación a una serie de televisión feminista}

"Pequeña Victoria" es una serie de televisión argentina que se transmitió en horario Premium por el Canal Telefe de Buenos Aires entre el 16 de septiembre y el 11 de diciembre de 2019 , con un total de 51 capítulos.

La serie ha sido catalogada por diversos autores (Erbiti, 2019; Freijo, 2019) como rupturista y disruptiva porque plantea modelos de co-maternidad y familia ajenos a las formas tradicionales y porque aborda temas polémicos como la identidad de género, los feminismos, la subrogación de vientre y el amor en todas sus formas (por ejemplo, se muestran las llamadas "parejas poliamorosas").

Desde que la serie salió al aire generó bastante interés, sobre todo en los grupos feministas argentinos, ya que aborda los temas de los techos de cristal, las 
dificultades que viven las mujeres en entornos de trabajo masculinizados, se muestran las llamadas "masculinidades deconstruidas" encarnadas en varones sensibles y capaces de expresar los afectos. Asimismo, se hacen severas críticas a los modelos de masculinidad hegemónica que se caracterizan y presentan como competitivos laboralmente, proveedores, con poca participación en las actividades del hogar o que intentan situar a las mujeres en tareas de servicio (de café, de comida, etc.).

La serie relata los vínculos de afectividad y convivencia que se tejen entre cuatro mujeres a partir del nacimiento, mediante vientre subrogado comercial, de una niña de nombre Victoria. Se relatan las estrategias, experiencias y formas no convencionales de ejercer una maternidad colectiva y compartida entre cuatro mujeres.

La historia empieza cuando Jazmín (una mujer de 40 años, sin pareja, con liderazgo empresarial), decide que quiere tener un hijo. Considerando que los permisos pre y posnatal ponen en desventaja a las mujeres en el contexto de trabajo y tomando en cuenta su avanzada edad, recurre a una clínica de fertilización para pedir informes acerca del embarazo subrogado.

Por intermediación de esa clínica de fertilización, Jazmín contrata a una joven de aproximadamente 20 años llamada Bárbara (Barbie) para el proceso de subrogación. Ambas firman un contrato en el que se establecen reglas, derechos y acuerdos en torno al embarazo. Dado que no es legal en Argentina el embarazo subrogado comercial, las dos mujeres acuerdan que se manejará como un embarazo altruista. El acuerdo queda así: la mujer contratante pondrá el óvulo y pagará una cantidad a Barbie por prestar su vientre; Barbie será el cuerpo gestante, el esperma provendrá de un donante anónimo.

Cuando llega el momento del parto, Bárbara va en uber al hospital. La uberista (Selva), al darse cuenta de que la mujer no tiene compañía, se queda y termina implicada en el proceso de alumbramiento y cuidado de la recién nacida. Cuando Jazmín, quien será la madre de ésta, llega al hospital, la mujer que estableció el acuerdo de subrogación de vientre le informa que las cosas se han complicado y sería oportuno que llamaran al donante de esperma. Jazmín acepta, pese a que eso no está estipulado en el contrato.

Desde las primeras escenas, llama la atención la continua reiteración de frases como: "Bárbara, este es el día más importante de tu vida" (médico partero), o "Este es el mejor día de tu vida (por dar a luz) (Selva)".

Una vez que nace la bebé y está en los cuneros, llega Ema, una mujer transexual, quien fue la donante de esperma. Así, en el hospital se encuentran las cuatro protagonistas de la serie: Emma (donante de esperma), Jazmín (donante de óvulo y quien pagó por la subrogación de vientre), Bárbara (gestante contratada, quien puso su cuerpo y amamantará a la bebé) ${ }^{1}$ y Selva (que asume un rol de cuidadora de todas las participantes de la serie).

\footnotetext{
${ }^{1}$ Pese a que la carga genética de la bebé no pertenece a Bárbara, el vínculo maternal es sostenido por argumentos corporales biologicistas: el parir y el fluido que durante los primeros meses de vida de un bebé adquiere un lugar central (la leche materna). Específicamente el fluido corporal de la leche materna ha sido objeto de estudio e interés para la antropología, la cual ha mostrado que, en distintas culturas, por ejemplo, el Cáucaso, los Balcanes o el Sahara del Norte de Africa, existen conceptos como "madre de leche" o "hermano de leche" y en lugares como Arabia Saudita hasta hay restricciones legales para contraer matrimonio con un pariente de leche. De acuerdo con Soler (2019), "La leche humana es el único alimento que produce el ser humano. No obstante, más allá
} 
Si bien al inicio Jazmín se muestra resistente a que Bárbara, Selva y Emma participen en la crianza de Victoria, conforme avanza la serie se muestra que no puede resolver todo y entonces acepta que participen activamente tanto en la crianza como en los cuidados que requiere la bebé. Acuerda con Bárbara que le pagará una suma extra y le seguirá prestando el departamento en el que vive mientras amamante, ya que Victoria no acepta leche de fórmula. Con estos elementos, la trama, los personajes y la perspectiva de la serie quedan establecidos.

\section{Feliz final: una descripción general de la obra}

"Feliz final" es una novela española escrita por Isaac Rosa (1974), que apareció en 2018 en la editorial Seix Barral de Barcelona. La obra habla de la historia de Ángela y Antonio, pareja que acaba de separarse, punto en el que inicia el relato. Este se cuenta de atrás hacia adelante, iniciando con la ruptura y finalizando con el "romance de película" con el que iniciaron la relación. La narración se presenta a través de monólogos que al principio corren paralelos o sobrepuestos, a veces se dirigen al otro, cargados de reproches y, otras veces, densos de nostalgia y resentimiento. Mientras más se avanza en la lectura, los monólogos se van acercando hasta formar un relato compartido que nos permite entender cómo fue la historia de la relación y los motivos de su final.

La historia de "Feliz final" ocurre en un contexto muy actual: la crisis, la inestabilidad económica, los cambios sociales consecuencia de ambas, las dificultades laborales en la profesión periodística, los cambios en el significado de las relaciones amorosas y en las formas de vivirlas y, punto de particular interés para nosotras, de la experiencia de la maternidad/paternidad marcada por las coordenadas de la realidad contemporánea descrita como telón de fondo de la relación de la pareja.

En cuanto a las tensiones derivadas de la maternidad/paternidad, encontramos que Ángela y Antonio tenían ideas distintas sobre la crianza y el cuidado de sus dos hijas. Además, daban una centralidad diferente al tema de la maternidad/paternidad en sus vidas. Otro aspecto relevante es que ambos actuaban roles y papeles propios de una división sexo/genérica del trabajo tradicional: Antonio principalmente preocupado y ocupado del trabajo, y Ángela encargada y volcada a la crianza de las hijas y a las actividades como cocinar, amamantar, sanar. En parte, aunque no exclusivamente, estas condiciones generaron distanciamientos, fisuras y problemas de pareja.

Desde el primer embarazo Ángela experimentó una constante preocupación por la salud de su hija, por lo que leía con aprehensión diversos libros en los que se ofrecía información acerca del desarrollo de los nonatos. Vivía concentrada, preocupada y consciente de los cambios de su cuerpo.

Por su parte, Antonio se mostraba afectivo con Ángela y la nonata, aunque no lo suficiente a los ojos de Ángela, quien señaló, en alguno de sus diálogos y a modo de reclamo, que Antonio siempre tenía prisa o que solo era afectivo en los breves instantes

de ser percibida como un alimento nutritivo y esencial, en muchas ocasiones, para la supervivencia del recién nacido, es una sustancia o fluido corporal biológico que, en caso de circular y ser compartida, es capaz de generar imaginarios y representaciones simbólicas que se podrán usar para la construcción de identidades y establecer relaciones entre individuos" (Soler, 2009, p 443). 
que su trabajo se lo permitía. Antonio, además, pensaba que la preocupación que mostraba Ángela por el tema del correcto desarrollo y trascurso del embarazo era desmedida; argumentaba que hasta en medio de las guerras nacen niños sanos y sin problemas.

Durante los primeros meses de vida de Ana, su primera hija, Ángela quería que el mundo compartido con Antonio, girara en torno al bebé y que se dejaran de lado otras dimensiones de la vida, por ejemplo, la recreativa, la doméstica, la sexual, la de pareja o la laboral. Por su parte, Antonio quería seguir con su vida cotidiana, ir a nadar, leer, salir con amigos a tomar una cerveza. Estas diferencias acarrearon los primeros conflictos entre ellos. A continuación, presentamos algunos fragmentos que muestran el distanciamiento irreparable entre Antonio y Ángela que inició en el postparto:

Antonio: la frase que más repetí en las siguientes semanas, de la que me faltó hacerme una camiseta, una taza de desayuno: cuando nace un hijo no se para el mundo. La pronuncié cada vez que durante mi permiso de paternidad quise hacer algo diferente a encapsularme en vuestro ovillo lactante: ir a la piscina, leer un libro, quedar con un amigo para tomar una cerveza, y no hacía falta que objetases nada, yo llevaba la frase por delante: cuando nace un hijo no se para el mundo. La seguí pronunciando durante meses, cada vez que mis intentos por hacer vida normal chocaban con tu estado de excepción maternal, cada vez que tú intentabas parar el mundo

Ángela: Claro que se para el mundo. Es decir, el tiempo. Se vuelve otro. Se amasa, se espacia. Se hace humano. Fue entonces cuando empezamos tú y yo a desplazarnos a velocidades diferentes, al nacer Ana. Y no es que tú avanzases más lejos, era más un moverte en círculos, un ir y venir. Como esos perros que acompañan el paseo adelantando y retrasando. Te quejabas a menudo de estar siempre tirando de nosotras, apremiándonos, resolviendo lo que dejábamos pendiente, organizando lo práctica para cumplir horarios, y por la calle, cargando en hombros a Ana y remolcándome a mí de la mano para seguir tu paso ... pero desde que nació Ana, mi tiempo se transformó. $Y$ también el tuyo, en un sentido distinto al que crees. Piensas que tus hijas te quitaban tiempo, pero en verdad te lo devolvían. El tiempo. La oportunidad de recuperar el tiempo, de frenar la deriva. Crees que por ellas ibas desbordado, pero no te dabas cuenta de que en verdad te contenían. Si no te despeñaste más veces fue gracias a ellas. (fragmento del libro Feliz Final: 144-145).

\section{Maternidad intensiva}

Una constante en las dos obras de ficción es la presentación florida de un modelo de maternidad que se ha extendido por el mundo en las últimas décadas: la llamada maternidad intensiva. En este trabajo mostramos la presencia de este tipo de maternidad en dos obras de ficción que corresponden a dos contextos geográficamente distantes (España y Argentina). Un aspecto en común en ambos contextos es la idea de que la maternidad es tan importante y valiosa que debería ser el centro en la vida de la madre, ya que se cree que su ejercicio permite hacer frente a una realidad social caracterizada por vínculos sociales frágiles. 
La maternidad intensiva es un modelo de maternidad con el que se plantea la posibilidad de rechazar la forma de vida actual: consumista, acelerada, centrada en el trabajo, individualista, impidiendo que las mujeres puedan dar el tiempo, dinero y esfuerzo necesarios para lo que consideran la buena crianza de los hijos. La maternidad intensiva a veces implica abandonar el propio trabajo, renunciar al éxito y al reconocimiento profesional (Hays, 1998)2.

La ideología de maternidad intensiva tiene éxito en distintos lugares del mundo, a pesar de que va en contra de los logros de las feministas de la segunda ola, quienes lucharon por el reconocimiento del derecho al trabajo, a la educación e hicieron fuertes cuestionamientos a la forma opresiva que la familia tradicional impone para el ejercicio de la maternidad.

Quizá uno de los principales recursos de la ideología de la maternidad intensiva es que presenta a los infantes como seres inocentes, frágiles, indefensos y extraordinariamente valiosos, que deben ser sobreprotegidos y a quienes hay que mantener alejados de las lógicas perversas del mercado y del sistema actual. Las mujeres que abrazan esta ideología asumen la responsabilidad total del cuidado y crianza de los infantes, haciendo de esto una exigencia moral cuyos tropiezos son pagados con enormes montos de culpa. Estas mujeres están dispuestas a invertir grandes cantidades de tiempo, recursos (económicos, emocionales, intelectuales, etc.) y energía a una maternidad alienante. Esta maternidad implica y requiere un intenso proceso de preparación y aprendizaje mediante manuales, asistencia a grupos de formación y profesionales de la psicología, puricultural, psicoprofilaxis, entre otros, que orienten y enseñen a entender las necesidades y las características de los niños y a atenderlos de manera "correcta" para lograr su excelente desarrollo. Como se puede apreciar, se habla de una educación y cuidado absolutamente centrados en las necesidades y el bienestar del niño, que por contraste implica secundarizar las necesidades y deseos de las propias madres (Hays, 1998).

Este modelo de maternidad sostiene y reproduce un ideal de madre caracterizado por ser responsable, amorosa y preocupada; así como por el estar dispuesta a priorizar el cuidado de los hijos sobre otras dimesiones de su vida (Castilla, 2009; Contreras \& Castañeda, 2016; Sanhueza, 2005). Desde este ideal sería indeseable que las madres expresen malestar, incomodidad o emociones negativas por las actividades que implica la crianza de infantes (Montecino, 1991, 2008).

\footnotetext{
${ }^{2}$ Esta idea de que la maternidad intensiva sea contestataria de la forma de vida contemporánea es cuestionada por otras autoras. Gimeno (2018) considera que, lejos de eso, hay una posible relación entre la maternidad intensiva y el neoliberalismo (aunque también puede plantearse que dicha relación no sea privativa con el neoliberalismo) al tornarse compatible con políticas públicas que conducen a la falta de apoyo a todo aquello que signifique facilitar a las mujeres su incorporación y avance en el mercado laboral y en la vida profesional: estancias infantiles, educación amplia, cuidado de la salud, entre otras. La maternidad intensiva pone el acento en la responsabilidad individual de cada mujer frente a sus hijos, recarga cada vez más el papel "histórico" de las mujeres como cuidadoras y en permanente servicio de otros, al mismo tiempo que exenta al Estado de su responsabilidad de atención a la infancia como grupo de reposición social. Igualmente, este modelo es útil para despresurizar el mercado laboral al regresar a las mujeres al hogar, con lo que se refuerzan los roles tradicionales de género.
} 
Este tipo de maternidad ha producido su propio ideal de "buena madre", a partir de nuevas y muy severas regulaciones morales. Sirve para evaluar a cualquier mujer en su desempeño como madre en el conocido esquema de buena/mala madre (Palomar, 2004) y se acompaña de una férrea "ortodoxia moral y corporal" (Gimeno, 2018) que da lugar a particulares ideas en torno a lo que "debe ser" el comportamiento materno y a lo que es una "óptima relación" con los hijos.

$\mathrm{Si}$ a partir de lo anterior regresamos a nuestra reflexión sobre la serie "Pequeña Victoria", vemos que tanto Bárbara, como Emma y Jazmín son personajes centrales y protagónicos que se caracterizan porque, aunque ejercen una maternidad colectiva y distribuida, todas siguen el modelo de maternidad intensiva. Por ejemplo, Jazmín, a pesar de sus resistencias iniciales, empieza a secundarizar el trabajo en su vida. Hace cada vez con más frecuencia home office para no alejarse de la niña, falta a reuniones de trabajo o cancela llamadas importantes (pese a que está compitiendo con otro compañero por un ascenso laboral), deja de asistir a reuniones en bares o a cenas con sus compañeros de trabajo; en lugar de ello, en cuanto sale de trabajar se va corriendo a casa para estar con la bebé.

Aparte, Jazmín deja de lado otros ámbitos (por ejemplo, el amoroso o sexual) de su vida por el cuidado de su Victoria, como se muestra en el episodio en el cual Manuel (su ex novio, compañero de trabajo y con quien hay todavía cierta atracción) la visita y ella no quiere hablar con él. Emma le dice que lo vea, que puede ser importante, pero Jazmín dice: "no quiero robarle tiempo a la bebé, debo estar con ella". Finalmente accede a verlo por cinco minutos.

En otro episodio, Manuel le cuenta a Jazmín que su esposa murió hace pocos meses y que le gustaría hablar de cómo fue su pérdida, y le pide que vayan a dar una vuelta o a tomar algo, pero ella se niega porque tiene que volver a casa a cuidar de la bebé.

En una ocasión, Jazmín está a punto de tener relaciones sexuales con Manuel, quien se va unos minutos al baño, mientras tanto ella escucha un audio en el que Emma le dice que llevaron al bebé al pediatra, pero que ya volvieron y que todo está bien. No obstante, Jazmín sale corriendo hacia su departamento para ver cómo está la bebé. Todo esto sin siquiera despedirse o darle una explicación a Manuel de por qué se va. En otra escena, Jazmín le dice a Emma: "la verdad es que al final no sé qué me pasa, últimamente siento que pierdo el control de todo" y Emma le responde: "Y obvio, ahora el control lo tiene ella (señala Victoria), por suerte".

Vemos pues que Jazmín, antigua feminista aguerrida que defendía su trabajo y confrontaba a los hombres, ha doblado las manos para ponerse al servicio de un nuevo amo que marca sus tiempos, intereses y prioridades: la nueva hija. Las compañeras de maternidad son útiles para ir marcando las "ventajas" de haberse convertido en madre y para ir mostrando a la audiencia las bondades de una maternidad intensiva que vale tanto como para abandonar los viejos ideales feministas. 
En cuanto a Emma, ella personifica una de las caras de la maternidad intensiva: la culpa, reflejada en una preocupación excesiva por la salud de la criatura3. Constantemente se está comunicando con el pediatra o llevando a la bebé a consulta, ya sea porque llora imparablemente, porque se cayó de la cama y quiere saber si está bien, porque no durmió lo suficiente, etc. Se informa constantemente sobre el desarrollo de la bebé, lo cual se lleva una gran cantidad de energía y de tiempo, ambas piezas importantes para una maternidad intensiva.

También Bárbara tiene otra lección fundamental que dar en relación con las maravillas de la maternidad intensiva, nos referimos a la necesidad de amamantar a la criatura a toda costa y por el mayor tiempo posible. Esto a pesar de todas las dificultades, incomodidades 0 animadversión que pueda tenerse por esta práctica. Este personaje presenta la dimensión biológica y "natural" de la maternidad y es útil para aleccionar acerca de un supuesto "instinto maternal" vinculado con el parto y las hormonas, pero también para insistir en que lo realmente importa no es ella, sino la niña que necesita de la leche materna para estar bien, aunque la madre no lo esté.

Por su parte, en la novela "Feliz Final", se relata que Ángela decidió reducir su jornada laboral para dedicarse también de manera intensiva a la maternidad. Se focalizó por completo en el cuidado de sus hijas, se dedicó a amamantar y tenerlas cerca para poder abrazarlas y jugar con ellas; abandonó su acelerado ritmo de vida usual, aun cuando eso implicó dejar de lado su vida de pareja o tener menos tiempo para sí; no quiso delegar la crianza o el cuidado de las niñas a nadie más (ni guarderías, ni la madre de Antonio).

Además, según lo que dice Antonio, Ángela mostraba una preocupación constante por evitar el malestar de ellas, protegerlas y hacerles una vida feliz. Incluso, se molestaba por los ruidos que hacían los vecinos en sus departamentos, considerando que eso podría despertar a las niñas. Otra característica de Ángela es su opción por una "maternidad natural", consistente en tener un parto vaginal, amamantar a libre demanda, el colecho, la vigilancia de sus propias costumbres para evitar las que podrían perjudicar a las criaturas, tales como reducir al máximo el consumo de bebidas alcohólicas. En suma, Ángela, eligió vivir centrada en las necesidades y requerimientos de las niñas (de hambre, de sueño, emocionales). En seguida, mostramos una discusión desarrollada entre Antonio y Ángela que, además de lo anterior, muestra (al igual que lo que ocurre con Emma en "Pequeña Victoria") la preocupación permanente de la madre por la salud de su hija mayor:

Antonio: No necesitabas cuarenta de fiebre, convulsiones, ni un silbido en el pecho: ya antes de aquel episodio te bastaba un llanto prolongado, o ni siquiera prolongado, un llanto medio, un llanto breve, un quejido, una sola vocal, un suspiro, para decretar el estado de excepción, soltar lo que estuvieras haciendo, saltar de la cama a mitad de la noche, correr por el pasillo pasando por encima de mí sí me adelantaba, salir de la ducha enjabonada, dejar un sartén en el fuego, detener el coche en mitad de la calle...no creo que fueses una madre histérica, y si alguna vez te lo dije así, te pido

\footnotetext{
${ }^{3}$ La vinculación de la excesiva preocupación por la salud y los sentimientos de culpa es muy conocida por psicólogos y psiquiatras, ya que suele esconder sentimientos ambivalentes inconfesables en relación con los hijos y hasta deseos agresivos o de destrucción en relación con ellos.
} 
perdón. Más bien pienso que eras una madre atenazada por un profundo sentimiento de culpa. De culpa preventiva. Por nada que le hubieras hecho a la niña, sino por todo aquello que deberías poder evitarle. El sufrimiento, esa idea tuya tan repetida entonces. Que la niña no sufra, decías. Que no sufra dolor. Que no sufra enfermedades. Que no sufra hambre. Que no sufra por no ver inmediatamente atendidas sus demandas de alimento, calidez, seguridad. Que no sufra por no encontrar a su madre. Que no sufra por despertar sola. Que no sufra por falta de contacto físico. Que no sufra por no tener todo el amor del mundo, que siempre será insuficiente. Que no sufra carencias afectivas que la condenen a padecer dificultades emocionales cuando sea adulta. Que no sufra tanto estrés que debilite su respuesta inmunitaria y afecte su sistema nervioso o metabolismo .... No quiero ser sarcástico, Ángela, estoy recordando de memoria lo que encontré en los libros que me diste a leer entonces, que leí porque quería entenderte y acercarme a ti. Y lo que encontré fue culpa, mucha culpa, una culpa infinita que se vertía sulfúrica sobre madres y padres ansiosos...

Ángela: Espera, que sigo yo, que lo recuerdo perfectamente: aquella genialidad que soltaste en una comida de amigos... aquella voz declamatoria que pusiste a interpretar tu paranoia del famoso fragmento cervantino: jdel poco dormir y del mucho leer, a las madres se les secó el cerebro, de manera que vinieron a perder el juicio, y vinieron a dar en el más extraño pensamiento que jamás dio loco en el mundo, y fue que les pareció convenible y necesario hacerse madres naturales! ...y evocaste un pasado mítico de cazadores y recolectores donde las madres llevaban todo el día a sus hijos colgados del pecho y dormía la familia en un mismo jergón y los bebés comían cuando tenían hambre, dormían cuando tenían sueño, contenían los esfínteres cuando les parecía educado, y lloraban si su madre desaparecía de su vista (fragmento del libro Feliz Final: 138-139).

En estos extractos del texto podemos ver otra vez los elementos presentes en "Pequeña Victoria", los que definen el modelo de la maternidad intensiva: colocación de las hijas en el lugar central de la existencia de la madre y desplazamiento de la pareja y/o del padre a un lugar periférico (si se le da); dejamiento y/o secundarización de otras dimensiones de la vida de la mujer-madre (ocio, trabajo, relaciones sociales, etc.); preocupación excesiva por la salud de las hijas; el abandono de los propios tiempos e intereses; las prácticas de amamantamiento a libre demanda, del colecho, del porteo constante, entre otras; el estudio concienzudo de la ideología de la maternidad intensiva en libros y manuales; la tendencia a aleccionar y juzgar a otras mujeres a partir de un rígido orden moral dictado por un ideal particular de "la buena madre"; y un discurso manifiesto en contra del feminismo de la segunda ola y sus planteamientos.

\section{Tensiones generacionales en torno a la maternidad y la crianza}

La maternidad es un fenómeno de género cuyo significado solamente puede comprenderse si es situado en el contexto histórico y cultural en el que se desarrolla (Contreras, 2020; Felitti, 2011; Montecino, 2008; Palomar, 2005). Otro elemento fundamental para comprender el significado de la maternidad es el que, también en cada contexto, tiene la infancia (Ariès, 1960), ya que hay una relación de sentido entre ambos. 
En el siglo XIX, se extendió la idea de que era necesario que las madres se prepararan, informaran y acudieran al asesoramiento de expertos (pediatras, pedagogos, gineco-obstetras, etcétera) para ejercer con propiedad la crianza de sus hijos. En esos años, los expertos promovían una educación con disciplina y severidad; por ejemplo, se hablaba de la importancia de que los niños tuvieran horarios definidos para la alimentación y el sueño, que no debían abrazarse o besarse en exceso, y que era importante dejarlos llorar para que se reforzaran sus pulmones y no fueran niños consentidos. La razón de este tipo de crianza, afirma Hays (1998), es que se pensaba que el niño era un ser peligroso, manipulador y que tenía que educarse, de lo contrario tendía a querer dominar a sus padres, ser rebelde, o podía quedarse en su condición de ser incompleto.

En las primeras décadas del siglo XX, los modos de ejercer la maternidad comenzaron a reorganizarse, surgieron nuevos imperativos y nuevas demandas sobre las mujeres madres, relata la misma autora. Los expertos comenzaron a hablar de la importancia del desarrollo emocional, cognitivo y comportamental del niño. Además, surgieron y se popularizaron las teorías del apego, cundió la idea de que una crianza estricta generaba traumas y efectos irreparables para los infantes. Se comenzó también a pensar en el bienestar del niño como una cuestión de Estado y se difundió la idea de que toda crianza debe estar focalizada en el bienestar del niño y en su buen trato. Dado que en ese siglo se incrementó la preocupación pública por la manera en que las mujeres ejercían la crianza, se intensificó para ellas la presión por volverse conscientes de la formación y la educación que daban a sus hijos. Esto, mediante la revisión constante de manuales y guías científicas que les sugerían cómo había que hacerlo.

También hacia mediados del siglo XX se comenzó a observar un nuevo tipo de crianza, más permisiva, y que consideraba importantes el amor y el cariño hacia el niño. Se comenzó a hablar de la importancia de que los infantes comieran y durmieran a libre demanda, que fueran abrazados lo más posible por sus madres. Se consideraba que su cercanía era lo mejor para los niños. Asimismo, se empezó a hablar de que toda práctica de educación infantil debe poner en el centro los deseos y necesidades naturales del niño (Hays, 1998).

El modelo de la maternidad intensiva nació en la década de los ochenta del siglo pasado y, como ya se dijo, se ha propagado por todo el mundo a partir de entonces perfilando nuevos significados y nuevas prácticas en relación con la maternidad y la crianza. Esta nueva forma de ser madre y de criar a los niños son representados en las dos obras de ficción que estamos analizando.

Con respecto a la serie "Pequeña Victoria", observamos que las cuatro protagonistas llevan a cabo una crianza permisiva, afectuosa, centrada en las necesidades y en los tiempos considerados adecuados para Victoria. Estas protagonistas todo el tiempo la tienen a la bebé en brazos, en cuanto llora la cargan o le dan alimento; si tiene cualquier malestar, la llevan al pediatra, la consienten y le platican amorosamente, y la bebé come y duerme cuando quiere (o cuando las adultas que la cuidan creen que quiere).

En un episodio observamos que este tipo de crianza permisiva se pone en conflicto y tensión con el modelo de mujer-madre de otra generación, el cual propone el 
uso de la disciplina en la crianza. En ese episodio Jazmín, presa de las contradicciones culturales de la maternidad frecuentes en las mujeres que trabajan y que, además, quieren cumplir a cabalidad con este extenuante y altamente exigente modelo de maternidad intensiva (Hays,1998), se siente cansada y complicada con tanto trabajo y el cuidado de Victoria. Por esta razón, decide contratar a una trabajadora doméstica (de nombre Alicia) para que realice el aseo de su casa y que se encargue del cuidado de la bebé

Jazmín selecciona a una mujer que habla de la importancia de la responsabilidad, de la honestidad, de la educación disciplinaria y estricta. Algunas de las propuestas de crianza de Alicia tienen que ver con alimentar a la bebé con horarios fijos, con no cargarla todo el tiempo "porque se mal acostumbra" y de dejarla llorar un poco "para que desarrolle paciencia y aprenda límites"; también critica el uso de pañales de tela porque dice que "esos los usaba su abuela y que hacen que la niña se roce". Tanto Emma, como Bárbara y Selva se muestran resistentes a la contratación de esta mujer, ya que la encuentran demasiado estricta y les molesta que le dé a Victoria juguetes rosados. Incluso, las tres se esconden de Alicia para cargar a la bebé, hacerle cariños y alimentarla sin un orden horario. Al final, Alicia renuncia, lo cual se ve en el siguiente diálogo:

Alicia (trabajadora doméstica): yo renuncio, eh, no paso ni un día más en su casa, no me dejaron trabajar, yo tengo una experiencia comprobada con más de 20 años, pero ellas hacen con su hija lo que se les da la gana.

Jazmin: y ¿qué pasó?

Alicia: Pasa... pasa que ella las tiene sometidas, que la beba hace lo que quiere, ustedes quieren criar a una chica desobediente, yo no pienso ser testigo de semejante cosa.

Jazmin: Pero si es una bebé, lo único que hace es comer, hacer caca y dormir

Alicia: y llorar, y ahora resulta que está mal visto que un bebé llore, pero favor que hace un ser humano ni bien nace, lo primero que nace es llorar, es natural llorar.

Alicia: (...) están equivocadas, mire usted, acá en su trabajo, cómo llegó hasta acá, con exigencia, con rigor, bueno, entonces, es así, ahora resulta que los chicos hacen lo que quieren cuando quieren, se duermen cuando quieren, estudian las tablas de multiplicar cuando se los dicta el corazón, ipor favor!

Jazmin: me parece que quizá yo me apresure al contratarla, Alicia, le voy a dar una compensación, quizá usted es un poco estricta y mi hija es una bebé que lo único que necesita es amor (episodio 4 de la serie "Pequeña Victoria")

En la obra literaria "Feliz Final" se expone un fuerte conflicto entre madres de dos generaciones distintas (Ángela y su suegra). La tensión deriva por las diferentes ideas y maneras de entender: 1) el significado de la maternidad para cada una; 2) las "buenas" prácticas de crianza de infantes; 3) el papel y el lugar que tienen el trabajo y la 
maternidad; 4) el lugar y tiempo que idealmente debiera destinarse para los hijos. Pese a que ambas se dicen feministas, es evidente que están posicionadas en distintos tipos de feminismos y entienden el ser feminista de modos muy diferentes.

La suegra le recrimina a Ángela las ideas de las madres contemporáneas (que en la obra también se llaman "madres naturales") que están dispuestas a dejar el trabajo, volver al espacio privado, amamantar, parir a los hijos sin epidurales, no usar anticonceptivos, parir en casa, amantar a libre demanda, colocar a los hijos en un lugar central privilegiado que las secundariza a ellas como sujetos, volver al discurso de instinto materno, ya que, según dice, esos ideales y prácticas van en contrasentido de una serie de luchas y demandas feministas que se lograron con mucho trabajo, por ejemplo, el derecho al trabajo, la posibilidad de apropiarse del espacio público, el uso de píldoras anticonceptivas, el parir con asistencia médica, separar la sexualidad y concepción, etc.

Ángela le dice a su suegra que las feministas de los 60 s u 80 s lo único que hicieron fue luchar por insertarse a un mercado laboral precario y masculinizado, en inferiores condiciones salariales y con mayores demandas de rendimiento y de disposición de tiempo que los hombres, dejando por ello en abandono a los hijos. A continuación presentamos un fragmento de esta discusión:

Ángela: ...A un lado de la mesa tenemos a una madre, ya abuela, que crió hijos hace más de treinta años, y a la que llamaremos Madreliberada: militante del feminismo de los setenta y ochenta, Madreliberada ejerció cuantos derechos fue conquistando: trabajar fuera de casa, regular su fertilidad con anticonceptivos, abortar, divorciarse. Del otro lado, una madre primeriza que llamaremos Madrenatural: también de convicciones feministas, Madrenatural ha decidido priorizar la crianza de su hija por encima de su carrera profesional, para espanto e incomprensión de familiares y amigos, y a ratos de su propio marido... ...Madreliberada le dice a su hija que no entiende cómo las mujeres han vuelto a caer en la trampa, y que esta vez se han metido ellas solas. Madrenatural vuelve los ojos hacia su marido, que le esquiva la mirada ...pero Madreliberada no se da por aludida y dice que es una pena, con todo to que ellas lucharon para liberarse del patriarcado, y que ahora haya mujeres que se lancen a él de cabeza y encima presuman de ello. Madrenatural suelta un resoplido bien sonoro, de hasta aquí hemos llegado. Madreliberada estira la cuerda otro poco: nosotras nos liberamos de la dominación de nuestros maridos, $y$ ahora van estas madres y se entregan felices a un nuevo amo $y$ señor: el bebé, que es el nuevo agente del patriarcado, la madre sometida a su hijo como antes lo estuvo al marido. Madrenatural desenfunda por fin: pero de qué liberación estás hablando, lo único que hiciste fue entragaros al mercado de trabajo sin modificarlo ni hacerlo igualitario, reproduciendo los patrones masculinos, en inferioridad de condiciones, aguantando doble jornada dentro y fuera de casa, y haciendo pagar un precio a vuestros hijos; si esa es la liberación, conmigo no cuentas, gracias...Madreliberada contraaataca: mira, no te consiento que digas que hicimos pagar un precio a nuestros hijos, ya está bien del discursito de las buenas madres y las malas madres, se puede querer a un hijo y darle todo lo que necesita sin llevarlo todo el día colgado a la teta; es que de verdad alucino de cómo habéis caído en la trampa, todo eso del instinto maternal, el vínculo exclusivo de madre e hijo, el misticismo de la crianza, joder, nos pasamos años luchando para que los 
hombres se hiciesen también cargo de sus hijos, y ahora vais y los echáis del dormitorio para poder dormir pegadas a vuestro bebé, y como eso todo lo demás: renunciáis a la epidural, gracias a la que nosotras vencimos la milenaria maldición bíblica de parir con dolor; veis con sospecha la píldora anticonceptiva por ser química, cuando a nosotras nos permitió ser dueñas de nuestros cuerpos, nosotras parimos, nosotras decidimos; os quedáis en casa cuidando al hijo mientras el marido trabaja, después de lo que nos costó escapar del hogar; permitís que el marido se desentienda porque no puede ni darle un biberón si se despierta de noche; renunciáis a todo placer pues el único placer es ver cómo maman vuestros hijos; y hasta algunas defienden los pañales lavables, que es como volver un siglo atrás; ;siempre acabo pensando que el más ferviente partidario de la crianza natural debe ser el papa!, porque todo esto parece el sueño húmedo de cualquier ultracatólico, el pack completo: la mujer en casa, sin píldora, el parto con dolor, la familia tradicional, la madre ascética y con profundo sentimiento de culpa, y todo sin que el patriarcado haya tenido que mover un solo dedo, jos habéis metido vosotras solitas en la jaula! Madrenatural ...dispara una bola más: pues para ser tan feminista, eso que has dicho no puede ser más machista; según tú, las mujeres somos tan tontas que nos han engañado creyendo que el parto natural o la crianza con apego eran un paso adelante en nuestra lucha por ser dueñas de nuestros cuerpos y de nuestras vidas; no te has parado a pensar que quizás lo que pasa es que no nos interesa el modelo de mujer que nos dejasteis: trabajar en un mercado laboral donde llevamos siempre las de perder, criar y cuidar en un mundo donde sobran los niños, eso sí, consolándonos con el discursito de conciliación, que por lo visto quiere decir escolarizar a los hijos desde que nacen, dejarlos en la guardería antes de que amanezca y recogerlos al anochecer; no, gracias. ...Madreliberada ... continua: no te das cuenta de que toda esa historia de reivindicar la maternidad se extiende justo cuando llega la crisis económica: en cuanto escasea el trabajo lo acaparan los hombres y mandas a las mujeres de vuelta a casa.... Yo no busco realizarme, interrumpe Madrenatural, hablamos demasiado de las madres y muy poco de los hijos, y deberían estar en el centro, porque vivimos en un mundo radicalmente antiniños; si no estás dispuesta a dar todo por tu hijo, no lo tengas, no es obligatorio (Fragmento del libro Feliz Final: 141-144).

Esta larga cita presenta de manera magistral y literaria, el intenso debate generacional no solamente en relación con las distintas maneras de comprender y vivir las experiencias de maternidad y crianza, sino que nos deja ver que, en dicho debate, también está en juego una lucha enmarcada en la política contemporánea de las identidades de género, esta vez no en relación con el otro sexo sino intragénero. Dicha lucha se relaciona con lo que señala Maalouf respecto a las "identidades asesinas" (Maalouf, 2009), porque del aniquilamiento del otro depende la propia existencia; para yo poder ser, el otro tiene que desaparecer. Yo soy la buena madre; yo soy la verdadera mujer; yo soy la feminista correcta, y las que no son como yo están mal, equivocadas y en el error.

Al respecto, conviene remarcar que en estudios previos (Asakura, 2005; Ávila, 2005; Palomar, 2005) ya se ha trazado y demostrado el vínculo entre maternidad, género e identidad femenina. En ese sentido, Palomar comenta:

La práctica de la maternidad parece sintetizar tanto las contradicciones como los ideales del género en nuestra sociedad, incluyendo en la producción de una experiencia 
femenina, compuesta por automatismos, tradiciones, costumbres y prescripciones sobre lo que una mujer debe ser, como práctica real o como posibilidad, es algo que a toda mujer se le plantea en algún punto de su proceso vital $(2005,54)$.

Por otra parte, los avances científicos, al alargar las posibilidades de vida, han hecho coincidir varias generaciones en un mismo momento, lo cual implica que en sus interacciones se dan evidentes desencuentros a propósito de una práctica que solía considerarse "natural" y no objeto de debates u opiniones. Ahora es más difícil que nunca tener respuestas únicas acerca de, ¿qué es ser mujer? ¿Qué es ser madre? Y las académicas nos preguntamos, además, ¿las mujeres madres colaboran con el sostenimiento del orden de género del status quo o son agentes que lo resisten y buscan transformarlo? ¿Ser madre es una identidad o es solo una práctica que coexiste simultáneamente con otras? ¿Se trata de una identidad o de una posibilidad de subjetivación? ¿Cómo entender las nuevas expresiones que se llaman de manera genérica "feministas" y que, no obstante, son tan distantes de las posturas anteriores?

\section{El instinto y el amor maternal: una experiencia desmesurada y desproporcionada}

La idea de amor maternal sustituyó a la idea del instinto materno que provenía de la biología animal (Badinter, 1981). Este tema del amor maternal está muy presente en la serie "Pequeña Victoria". En su desarrollo se escuchan distintas frases que hablan de la maternidad como una experiencia de amor inconmensurable. Por ejemplo, un episodio de la serie, Emma le relata al pediatra de Victoria la negociación de vientre subrogado, pese a que esto está prohibido en Argentina. Llama la atención que Emma cierra el relato diciéndole, "lo único que importa es el amor (hacia un hijo), a veces la única opción que queda es la clandestinidad". Luego, en un diálogo entre Emma y Jazmín en otro episodio, Jazmín le dice a Emma: “¿Te enamoraste alguna vez?" Emma responde: "Amor, amor, no, ¿vos?" Jaz dice: "esto es amor (viendo a la bebé), esto es verdadero amor de mamá".

En "Pequeña Victoria" todos los personajes (Emma, Jazmín, Selva, Bárbara, el pediatra, las amigas transexuales de Emma, Manuel, un pintor, etc.) muestran una afectividad, ternura y amor desbordados, un interés desmesurado por cuidar, proteger, alimentar y hacer cariños a Victoria.

En "Feliz Final" también se habla de cómo la experiencia de la maternidad es la de un amor desmedido, diferente y único, que inicia con el nacimiento de los hijos. En repetidas ocasiones Ángela habla de cómo cambió significativamente su vida a partir del nacimiento de sus hijas, señalando los ajustes que debió hacer en el manejo de sus tiempos, ritmos de vida y prioridades, todo a partir del amor maternal.

\section{El ideal de una maternidad colectiva y sin hombres}

Otro elemento común a las dos obras es la fantasía o intención de lograr una comaternidad o una maternidad colectiva entre mujeres que no comparten vínculos sanguíneos o de parentesco. Además, esta maternidad se piensa sin hombres. En el caso de "Pequeña Victoria", observamos que cuatro mujeres se organizan y llevan a cabo la crianza. Llama la atención que en la serie nunca aparece la familia de Jazmín y, en los 
casos que aparece la familia de Bárbara, es solo para pedir dinero. La familia de Emma es un grupo de amigas y de vínculos recompuestos: la matriarca del colectivo transexual, las amigas-hermanas elegidas, más no la familia consanguínea. En este punto pueden plantearse algunas preguntas como, ¿Cómo se establecen los roles, acuerdos y actividades de estas mujeres en torno al cuidado y crianza de la bebé Victoria? ¿Cómo o por qué se piensa en crear una serie con vínculos no sanguíneos?

En "Feliz Final" tampoco se habla de la participación de la familia como una red de apoyo que interviene o tiene presencia en la crianza de los hijos. Sin embargo, sí hay una extensa narración en la que Ángela cuenta a Antonio cómo una amiga suya le propone que se vayan a vivir juntas y lleven a cabo un ejercicio de maternidad comunitaria y sin hombres:

Nos vamos juntas, me dijo Luisa cuando me quejé de tu falta de entusiasmo, ella todavía quejándose de su reciente divorcio: nos vamos juntas tú y yo, Ángela, nos vamos juntas con nuevas hijas y formamos una comunidad de madres; conozco unas cuantas madres separadas o solteras que se apuntarían con los ojos cerrados; cada vez hay más grupos de crianza cooperativa, familias desbordadas que se organizan para repartirse tareas y darse apoyo mutuo, pero deberíamos ir más allá, largarnos unas cuantas a tu casa del pueblo y vivir juntas y criar juntas y apoyarnos y cuidarnos, en plan tribu; no te rías, Ángela, yo he terminada muy escaldada del modelo papá-mamá-hijos-solos-frenteal-mundo, es una trampa, primero caemos en la trampa del amor y después en la trampa de la familia nuclear, nos deja a las madres solas o como mucho con algo de ayuda de los padres (Fragmento del libro Feliz Final: 91-92).

Vemos aquí una especie de realización de la fantasía de autoengendramiento proyectada en colectivo: nosotras podemos solas, los hombres no son necesarios o son francamente indeseables. En "Pequeña Victoria" hasta el padre de la niña es una mujer y los otros personajes masculinos son representados como figuras borrosas y torpes. En "Feliz final" Ángela acaricia el sueño de deshacerse de un marido que no entiende su forma de criar a sus hijas y no hace más que cuestionarla. Un sujeto sometido sin queja al status quo del capitalismo tardío. Se presenta el sueño romántico de un mundo femenino que, por serlo, estaría exento de todas las lacras que los varones han puesto en el mundo, según esta visión. Ambas obras presentan un mundo partido en dos por una lucha entre los sexos, a los que se entiende de manera polarizada y antagónica. Hasta las criaturas en ambas obras son niñas; se nos ocurre, ¿qué pasaría en ambas si hubiera hijos varones?

\section{Conclusiones}

Las obras analizadas en este trabajo corresponden a distintas prácticas semióticas (una es una serie de televisión y la otra es una obra literaria), que también han sido elaboradas en distintos espacios geográficos (España y Argentina), pese a ello, en ambas se muestran elementos compartidos en torno a lo que se entiende por maternidad y las formas ideales de llevarla a cabo por las mujeres contemporáneas. Esto reafirma que en las prácticas expresivas (televisión, literatura, streaming) es común que se reproduzcan y 
produzcan significados y deseos que modelan las prácticas y roles sociales de los sujetos, tal como lo han sostenido diversos autores (Bueno, 2006; Galán, 2006; Guarinos et al., 2019; Menéndez \& Zurian, 2014; Sarlo, 1997 citado en Bueno, 2006; Simelio, 2010).

Además, en ambas prácticas semióticas destaca la emergencia de la culpa, la preocupación por el bienestar del infante, la responsabilidad y la implicación intensiva con el rol de cuidados por parte de las mujeres más jóvenes. Así como a la secundarización o dejamiento de las funciones laborales, profesionales, etc. Estos elementos forman parte de un ideal de maternidad intensiva que ya han descrito previamente algunas autoras (Castilla, 2009; Contreras \& Castañeda, 2016; Contreras, 2020; Hays, 1998; Sanhueza, 2005). Esto nos lleva a identificar que, tal como lo ha propuesto De Lauretis (1992), en estas prácticas semióticas se producen y exhiben signos, cualidades y expresiones asociados con una ideología dominante e imperante en un tiempo y contexto determinado.

Asimismo, en las dos obras se muestran nuevos significados de lo que se entiende por feminismo. Se advierte un vaciamiento semántico del término "feminismo" que, en ciertos momentos se plantea como mujerismo y, en otros, cae en una exaltación de la identidad femenina apelando a argumentos esencialistas, como el poder que se deriva de la capacidad biológica de gestar y parir.

En ambas obras se muestra una tensión intergeneracional en cuanto a lo que se entiende e implica la maternidad. Mientras la generación de abuelas expresa una maternidad basada en la disciplina, que busca y promueve la autonomía de la mujer, en la generación de las madres contemporáneas se descalifica este tipo de crianza y hasta se ridiculiza.

Por su parte, la generación de las madres se caracteriza por una crianza permisiva, afectuosa, excesivamente centrada en las necesidades del infante. De acuerdo con Hays (1998) la maternidad intensiva y permisiva apareció desde mediados del siglo $\mathrm{XX}$, al menos en países como Estados Unidos de América -contexto que analiza la autora-; sin embargo, ahora, casi 70 años después, parecería que ese discurso sigue vigente, se ha extendido y ha cobrado bastante fuerza y visibilidad, lo cual puede discutirse al plantear que no se trata del mismo discurso, sino de su reformulación en clave contemporánea y globalizada a partir de los elementos de la época.

Se presenta una relación simbiótica entre madres e hijas en ambas obras, ante lo cual nos surgen las siguientes preguntas: ¿A qué obedece esta relación simbiótica entre madre e hijo? ¿Qué se busca al establecer como ideal este tipo de relación entre madre e hijo? ¿Por qué en estas diadas se excluye al padre, se le muestra como menos diestro o se le descalifica? ¿Qué hay detrás de esta necesidad de borrar al padre y a cualquier presencia masculina?

"Pequeña Victoria" resulta un producto sumamente contradictorio, ya que, aunque incluye una serie de temas actuales controversiales, tales como el contrato de vientres subrogados, la transexualidad, la prostitución o las tecnologías de reproducción asistida, la maternidad en soltería, el mensaje final es sumamente tradicional: la maternidad lo es todo en la vida de las mujeres y exige el abandono de cualquier otro interés o deseo. Sin embargo, es tan intensa que se necesitan cuatro para llevarla adelante. 
Pese a que "Pequeña Victoria" es una serie planteada como rupturista y feminista, no hay una interpelación o cuestionamiento a los cautiverios de la maternidad, por el contrario, se promueve un ideal de maternidad intensiva, permisiva, centrada en las necesidades y deseos de Victoria.

En tanto, "Feliz Final" muestra de mejor manera la complejidad de las relaciones afectivas que involucran los lazos parentales en el contexto de la vida contemporánea, además de mostrar de manera crítica los componentes de la maternidad intensiva actual Una muestra de ello es la discusión citada entre las madres de dos generaciones y los argumentos que se dan en contra de este tipo de maternidad.

Finalmente, resulta oportuno preguntarse ¿cuáles serán los efectos de este tipo de maternidad en la relación de pareja? ¿Qué bstáculos plantea este tipo de maternidad intensiva para la paternidad y, más aún, para la corresponsabilidad? ¿Qué efectos tienen estas prácticas de crianza en los propios hijos? Sin duda, muchas de estas preguntas exceden el objetivo de este trabajo, pero abren nuevos temas y agendas en la investigación de género, familias y las maternidades que convendría fueran abordadas en futuras investigaciones.

\section{Bibliografía}

Ariès, Philippe. (1960): El niño y la vida familiar en el Antiguo Régimen. Madrid: Taurus.

Asakura, Hiroko (2005): "Cambios en los significados de la maternidad: emergencia de nuevas identidades femeninas", en M. Torres (ed.): Nuevas maternidades y derechos reproductivos, p. 61-98. D. F.: Colegio de México.

Ávila, Yanina (2005): "Mujeres frente a los espejos de la maternidad: las que eligen no ser madres”, en Desacatos. Revista de Antropología Social, p. 107-125.

Bueno Fischer, Rosa: (2006) "El ejercicio de ver: medios y educación”. Traducción: A. Abraowski y D. Simas Baptista. En: Dussel y Gutiérrez (comp.): Educar la mirada. Políticas y pedagogías de la imagen, p. 165-177. Buenos Aires: Manantial/Flacso Argentina /Fundación Gosde.

Castilla, María (2009): Continuidades y cambios en los sentidos y experiencias de la maternidad argentina. D.F., México: CIESAS

Contreras, Karla (2020): Embarazos situados: subjetividad y experiencia en mujeres gestantes en Guadalajara, México. México: CIESAS.

Contreras, Karla \& Castañeda, Liliana (2016): "Tensiones entre el cuerpo productivo de la mujer y la normatividad de género en torno a la maternidad", en Revista Latinoamericana de Estudios sobre Cuerpos, Emociones y Sociedad, Vol. 21, Núm. 8, p. 10-20. 
De Lauretis, Teresa. (1992): Alicia ya no. Feminismo, Semiótica, Cine. Madrid: Cátedra.

Badinter, Elizabeth. (1981): ¿Existe el amor maternal? Historia del amor maternal. Siglos XVII al XX. Barcelona: Paidós/Pomaire.

Erbiti, Juan Tomás. (10 de diciembre de 2019): “¿Quiénes darán el sí en el final de pequeña victoria?”, Períodico El Clarín, Buenos Aires. Disponible en: https://www.clarin.com/espectaculos/tv/-daran-final-pequena-victoria0 fbF4AmW-.html.

Felitti, K. (2011): "Entre el deber y el derecho: maternidad y política en la Argentina del siglo XX". En: Felitti, K. (coord.): Madre no hay una sola. Experiencias de maternidad en la Argentina, p. 23-52. Buenos Aires: Ediciones CICCUS.

Freijo, María Florencia. (2019). "Pequeña Victoria: una nueva ética de los afectos", en Revista Anfibia. Disponible en: http://revistaanfibia.com/ensayo/pequenavictoria-una-nueva-etica-de-los-afectos/4

Galán, Elena. (2006): "Personajes, estereotipos y representaciones sociales. Una propuesta de estudio y análisis de la ficción televisiva”, en ECO-POS, Vol. 9, No. 1 , p. 58-81.

Gimeno, Beatriz. (2018): La lactancia materna. Política e identidad. Valencia: Cátedra / Universitat de Valencia.

Guarinos, Virginia; Gordillo, Inmaculada; Ramírez-Alvarado, Mar; Jiménez, Jésús; \& Hermida, Alberto. (2019). "Masculinidades de ficción televisiva y retroalimentación online. Jóvenes y adolescente en red-ados fuera y dentro de Física o química y El Internado", en Comunicación y desarrollo en la era digital. II Congreso Internacional de la AE-IC (20 P.)

Maalouf, Amin. (2009): Identidades asesinas. Madrid: Alianza editorial.

Montecino, Sonia (1991). Madres y huachos: alegorías del mestizaje chileno. Santiago: Editorial Catalonia.

Montecino, Sonia (2008). "Hacia una antropología del género en Chile", en Montecino, Sonia (compiladora): Mujeres chilenas fragmentos de una historia. Santiago: Editorial Catalonia.

Hays, Sharon. (1998): Las contradicciones culturales de la maternidad. Barcelona: Paidós. 
Menéndez, María Isabel; Zurian, Francisco. (2014):" Mujeres y hombres en la ficción televisiva norteamericana hoy", en Anagramas Rumbos y Sentidos de la Comunicación, Vol. 13, No. 25, p. 55-71.

Palomar, Cristina. (2004): "Malas madres: la construcción social de la maternidad", en Debate Feminista, Vol. 30, Año 15, p. 12-34, ISSN 0188-9478.

Palomar, Cristina (2005): "Maternidad: historia y cultura", en Revista Estudios de Género. La Ventana, p. 35-67.

Hidalgo-Mari, Tatiana. (2017): "De la maternidad al empoderamiento: una panorámica sobre la representación de la mujer en la ficción española", en Prisma Social, No. Especial 2, p. 291-314.

Sanhueza, Tatiana (2005): "De prácticas y significancias en la maternidad, transformaciones en la identidad de género en América Latina, en La Ventana, p. $146-188$.

Simelio, Núria. (2010): "La Representación de las Relaciones Sociales en las series de ficción digitales creadas específicamente para internet", en La televisión como contribución a la alfabetización digital, p. 1-11.

Soler, Elena. (2019). "Procreación, sustancia compartida y parientes de leche en el sur de Europa", en AlBR Revista de Antropología Iberoamericana, Vol. 14, No. 3, p. 441-462. 